DOI: http://dx.doi.org/10.18764/2358-4319.v11n2p215-237

\title{
Identidade, História e Educação na Comunidade Quilombola de Castanhão em Ibipitanga/BA
}

\author{
Angelita Rosa de Oliveira ${ }^{1}$ \\ Feliciano de Mira²
}

\section{RESUMO}

A construção histórica da identidade remanescente quilombola das crianças do Ensino Fundamental da Comunidade de Castanhão, (Ibipitanga, BA), efectua-se por meioda transmissão da cultura e valores, desde a fundação do povoado e do sistema oficial de ensino. O nosso objetivo foi compreender a reconstituição da identidade quilombola e como os valores da comunidade são transmitidos, assim como os métodos aplicados na educação escolar das crianças quilombolas. A coleta de dados foi efetuada a partir da aplicação de questionários a alunos e professores e a realização de entrevistas semiestruturadas com representantes da comunidade. A análise dos resultados mostra que a educação escolar é tributária da identidade quilombola, e colabora para a formaçãoda identidade negra da Comunidade e fortalecimentodo seu percurso histórico. A Escola Pe. Aldo Coppola necessita articular a educação e a identidade num processo pela socialização do quilombola.

Palavras-chave:Comunidade de Castanhão. Remanescente quilombola. Identidade quilombola.

\section{Identity, History and Education in the Community Quilombola of Castanhão in Ibipitanga/BA}

\section{ABSTRACT}

The historical construction of the remaining quilombola identity of the children of the Fundamental Education of the Community of Castanhão

1 Mestre em Ecologia Humana e Gestão Socioambiental - PPGEcoH - UNEB. Membro do Grupo de Pesquisa em Sócioeconomia do Desenvolvimento (GP-SEDES), licenciada em Pedagogia. E-mail: angelitarosabrasil@gmail.com

2 Doutor em EHESS Écoledes Hautes Étudesen Sciences Sociales de Paris. Doutor em Sociologia Económica e das Organizações pelo ISEG - Instituto Superior de Economia e Gestão da Universidade Técnica de Lisboa. Pós-Doutorado em Estudos Culturais Comparados no Centro de Estudos Sociais da Universidade de Coimbra. Docente do Programa de Pós-Graduação em Ecologia Humana e Gestão Socioambiental - PPGEcoH - UNEB. Coordenador do Grupo de Pesquisa em Sócioeconomia do Desenvolvimento (GP-SEDES). E-mail: felicianomira@hotmail.com 
(Ibipitanga, BA), is carried out through the transmission of culture and values, from the foundation of the village and in the official system of education. Our objective was to understand the reconstitution of quilombola identity and how community values are transmitted, as well as the methods applied in school education of quilombola children. Data collection was carried out through the application of questionnaires to students and teachers and semi-structured interviews with representatives of the community. The analysis of the results shows that the school education is tributary of the quilombola identity, and contributes to the formation of the black identity of the Community and strengthening of its historical course. The School Fr. Aldo Coppola needs to articulate education and identity in a process for the quilombola's socialization.

Keywords: Community of Castanhão. Remnant quilombola. Quilombola identity.

\section{Identidad, Historia y Educación en la Comunidad Quilombola de Castanhão en Ibipitanga / BA}

\section{RESUMEN}

La construcción histórica de la identidad remanente de los niños de la Enseñanza Fundamental de la Comunidad de Castanhão (Ibipitanga, $B A)$, se efectúa a través de la transmisión de la cultura y valores, desde la fundación del pueblo y en el sistema oficial de enseñanza. Comprender la reconstitución de la identidad quilombola y cómo se transmiten los valores de la comunidad, así como los métodos aplicados en la educación escolar de los niños quilombolas. La recogida de datos fue efectuada a partir de la aplicación de cuestionarios a alumnos y profesores y la realización de entrevistas semiestructuradas con representantes de la comunidad. El análisis de los resultados muestra que la educación escolar es tributaria de la identidad quilombola, y colabora para la formación de la identidad negra de la Comunidad y fortalece su recorrido histórico. La Escuela P. Aldo Coppola necesita articular la educación y la identidad en un proceso por la socialización del quilombola.

Palabras clave: Comunidad de Castanhão. Remanente quilombola. Identidad quilombola. 


\section{Introdução}

A construção histórica da identidade remanescente quilombola de crianças do Ensino Fundamental da Comunidade de Castanhão, (Ibipitanga, Bahia), efectua-se por meio da transmissão da cultura e valores, desde a fundação do povoado. A educação e a cultura são constructos inter-relacionados: "É pela educação que os sujeitos aprendem a cultura e constroem sentidos para suas experiências individuais e coletivas. A inter-relação entre os dois campos do conhecimento é possível, já que ambos se ocupam do ser humano" (SOUZA, 2015), enquanto que cultura é a soma de conhecimentos, técnicas, valores conhecimento simbólico preservado social e historicamente (BOYD; RICHERSON, 1985; MIRA, 2016). A educação escolar é tributária da identidade quilombola, colaborando para o estabelecimento da identidade negra e o fortalecimento da consciência histórica no intuíto de compreender como são acolhidos na educação escolar e formativa das crianças quilombolas.

\section{Teoria}

A identidade é uma realidade presente nas sociedades humana, Stuart Hall tratou a identidade dentro dos estudos culturais, a partir da sua experiência de emigrante, depois passou para estudos sobre a raça e a etnicidade, para concluir que as identidades são construídas por comparação com outras identidades. Essa construção pelas diferenças apresenta oposições binárias que são transmitidos pelos discursos, modos de ver, ser e agir no mundo integrado a valores, crenças, e práticas socioculturais para a produção do significado (HALL, 2000). A identidade está inserida no contexto sociocultural, privilegiando as dimensões pessoais e coletivas do grupo social de pertença, dessa forma coabita e constrói-se por meio dos diferentes grupos de que faz parte e dos papéis que desempenha.

Esta diferença pode ser vista como diversidade, heterogeneidade e hibridismo que embora enriquecedora, está ligada à subjetividade e sugere a compreensão sobre o eu, os sentimentos e pensamentos, reproduzidos dentro de ambientes onde a linguagem e a cultura dão significado à experiência identitária (WOODWARD, 2000; MIRA, 1997). A necessidade de construir uma identidade, que, no entanto, se mostra transitória por estar num processo contínuo de construção, levando 
em consideração a duplicidade de culturas envolvidas. Concomitantemente, para Bauman (2003) a identidade se constrói em referência aos vínculos estáveis e conflitos que conectam as pessoas umas às outras. Essa ambivalência é uma luta contra a dissolução e a fragmentação onde exclusão e inclusão se misturam e complementam.

Hall (2006) identifica três conceitos de identidade que se relacionam às visões de sujeito ao longo da história: sujeito do iluminismo, sujeito sociológico, e sujeito pós-moderno. $O$ sujeito do iluminismo concentra no eu a identidade de um indivíduo dotado de razão, consciência e ação, sendo um conceito individualista do sujeito e de sua identidade. O sujeito sociológico, levando em consideração a complexidade do mundo moderno, o seu núcleo interior é constituído na relação com outras pessoas, cujo papel é de intervenção da cultura. $\mathrm{O}$ sujeito na Sociologia forma-se na interação com a sociedade, em um diálogo contínuo com os mundos interno e externo. Finalmente, o sujeito pós-moderno não tem identidade fixa, essencial ou permanente. A identidade torna-se uma "celebração móvel": formada e transformada continuamente em relação às formas pelas quais somos representados ou interpelados nos sistemas culturais que nos rodeiam (HALL, 2006).

A visão de sujeito apropria-se dos contornos históricos e não biológicos, e o sujeito adota identidades múltiplas em diferentes contextos, que são, via de regra, contraditórias, impulsionando-lhe as ações em inúmeras direções, de forma que suas identificações são continuamente deslocadas. Então, identidade, se, de um lado, desestabiliza identidades estáveis, de outro, abre a possibilidade de progresso de novos sujeitos. A sociedade está em contínua mutação, fazendo com que novas identidades surjam continuamente. Sendo assim a identidade do sujeito pode estar "descentradas", isto é, fragmentadas e deslocadas, sendo que, como consequência, não seja possível mostrar afirmações conclusivas sobre que é identidade.

As comunidades negras rurais que passaram a ser categorizadas como remanescentes quilombolas, aumentaram a sua visibilidade, sob diversas formas de organização e (auto) denominação, se apropriaram da nominação como estratégia de coletivização da luta política em prol de direitos (SANTANA, 2008). Embaladas pelos movimentos sociais do último quartel do século passado, como o Movimento Negro, vêm demandando políticas públicas de acesso à terra, educação, saúde, entre outros. 
A educação é para Freire (1996, p. 109), "um ato de intervenção no mundo" especialmente na sociedade brasileira multiétnica e de grande diversidade cultural, daí a importância no cumprimento da Lei no 10.639/03³, que torna obrigatório o ensino de História e Cultura Africana e Afro-Brasileira na matriz curricular da Unidade Escolar do Ensino Fundamental. Para isso, é essencial o entendimento das concepções que estabelecem os espaços formativos, o valor e os limites da educação como processo de aperfeiçoamento e de libertação do homem, Cabanas (2002), pois as teorias de educação pretendem explicar o sentido e dimensão, conceptual e real do processo formativo. Desta maneira, as teorias de educação devem ser entendidas na forma como se entrelaçam no processo de orientação dos agentes envolvidos atendendo ao contexto histórico.

A importância dessas teorias para a educação escolar, é fundamental como articuladoras de práticas pedagógicas que se pretendem ser emancipatórias e, sobretudo, didáticas, de modo a transformar a postura do professor de transmissor para mediador de desafios formativos. O processo de transmissão de conhecimentos requer uma reflexão profunda sobre os fins da educação, que envolvem percepões sobre a sociedade. As mudanças culturais globais, a mundialização de mercados e disseminação da internet, tendem à padronização de costumes e consumos, ao tempo que acentuaram a defasagem educacional e o aumento das desigualdades.

No Brasil, democratizar o ensino não significou democratizar o conhecimento, a capacidade educacional de inserir os educandos no cenário mundial do conhecimento não se tem realizado. O conhecimento, tanto tem aspectos compartilhados pelo grupo social ao qual pertence quanto aspectos pessoais, em virtude da natureza do seu processo próprio de construção. O resultado do Pisa - Programa Internacional de Avaliação de Alunos - é uma avaliação internacional que mede o nível educacional de jovens de 15 anos por meio de provas de Leitura, Matemática e Ciências, realizado em 70 países, o Brasil ficou na 63a posição em ciências, na $59^{\mathrm{a}}$ em leitura e na $66^{\mathrm{a}}$ colocação em matemática (MORENO, 2016). Tal significa que a globalização funciona segundo eixos de influência e reprodução de modos de produção apesar da atribuição de verbas significativas do PIB (MIRA, 2014).

3 Altera a Lei no 9. 394, de 20 de dezembro de 196, que estabelece as diretrizes e bases da educação nacional, para incluir no currículo oficial da Rede de Ensino a obrigatoriedade da temática "História e Cultura Afro-Brasileira", e dá outras providências. 
Numa perspetiva de coesão interna, a obtenção do título da terra comunidades quilombolas pode elevar a qualidade da educação oferecida às comunidades quilombolas, com apoio financeiro aos sistemas de ensino para a formação continuada de professores para áreas remanescentes de quilombos, ampliação e melhoria da rede física escolar e produção e aquisição de material didático (MEC, 2016). Segundo a Fundação Cultural Palmares existem no Brasil, 1.209 comunidades quilombolas e 143 áreas já tituladas, envolvendo aproximadamente 151 mil alunos matriculados em 1.253 escolas localizadas em áreas remanescentes de quilombos, estando 75\% destas matrículas na região Nordeste (MEC, 2016).

Para o Ministério da Cultura, (MEC, 2016) os principais problemas do ensino nas comunidades quilombolas, derivam do fato das unidades educacionais estarem longe das residências dos alunos e as condições das escolas serem precárias, geralmente construídas de palha ou de pau-a-pique. Acresce a escassez de água potável e as instalações sanitárias serem inadequadas. Por outro lado, a maioria dos professores não são capacitados adequadamente e o número é insuficiente para atender à demanda. Em muitos casos, uma professora ministra aulas para turmas multisseriadas. Poucas comunidades têm unidade educacional com o ensino fundamental completo. A Comunidade de Castanhão enfrenta inúmeros problemas na educação por isso, a obtenção da certificação e da titulação da terra devem ser metas que precisam ser fomentadas.

\section{Percurso metodológico}

A Comunidade de Castanhão fica a 19 km da sede do município de Ibipitanga onde residem 103 famílias, com população aproximada de 335 habitantes ${ }^{4}$, é a única comunidade negra rural do município, e surge como "remanescente quilombola" em um contexto social em que os seus membros se autorrepresentam "pretos" e/ou remanescentes quilombolas.

Na aplicação dos instrumentos (03/11/2016), a Escola Padre Aldo Coppola contava com 13 professores, e de acordo com o censo escolar, a escola atendia um total de 123 alunos $^{5}$, distribuídos nos turnos: matutino, vespertino e noturno. Nesse sentido, foram convidados para

4 Informação do Programa Saúde Familiar (PSF) Agente Comunitária Ivonete Silva (2016).

5 Fonte: QEDU (2016) 
participar respondendo aos questionários 10 professores e 20 alunos, com questões fechadas e abertas, complementados com as narrativas de 4 entrevistados idosos guardiões das culturas e tradições da Comunidade de Castanhão. Assim, unindo a área de educação, cultura e história, procura-se apresentar neste estudo uma visão do processo de criação da identidade quilombola. Nesse sentido, os questionários foram divididos pelas variáveis: Comunidade, Identidade Quilombola e Integração Identitária, e depois de compostos em dimensões.

a) Comunidade- trata-se do perfil sociodemográfico de professores e alunos, (idade, sexo, raça/cor, religião, tipo de moradia, condição de ocupação da casa, saneamento básico, desenvolvimento socioeconômico, número de pessoas que moram na casa).

b) Identidade Quilombola- destaca-se a relação entre a cultu$\mathrm{ra}$, a identidade e a subjetividade quilombola, baseando-se no imaginário social construido sobre esses sujeitos, (o que é quilombo; a importância do reconhecimento como remanescente de quilombo; e como pode influenciar sua vida, e se acredita que o conhecimento recebido por meio da educação influencia na identidade quando a comunidade for reconhecida como remanescente quilombola).

c) Integração Identitária- busca conhecer se a escola tem trabaIhado com projetos voltados a comunidade negra (obediência a diretrizes oficiais);

As entrevistas aos idosos foram realizadas com base em palavras-chave, criadas no momento de cada entrevista, adaptando a linguagem e a forma de elaborar, e a partir das narrativas dos idosos, permeavam a história da comunidade desde a fundação e a perseverança dos fundadores; manifestações culturais, como as festas religiosas, dança e música como o Reisado.

\section{Dados Demográficos de Alunos e Professores}

Os inquiridos são compostos por 14 alunos do sexo masculino e 6 alunas do sexo feminino. Os 10 professores inquiridos, 2 são do sexo masculino e 8 do sexo feminino. Isso reflete a tendência nacional as muIheres somam $81,5 \%$ do total de professores da educação básica brasileira. (HARNIK, 2011, s/p.). 
Tabela 1 - Faixa etária dos alunos

\begin{tabular}{c|c}
\hline Faixa etária & No de alunos \\
\hline 9 a 12 anos & 17 \\
13 a 16 anos & 2 \\
17 a 20 anos & 1 \\
\hline Total & $\mathbf{2 0}$ \\
\hline
\end{tabular}

Fonte: Elaborado pelos autores

Tabela 2 - Faixa etária dos professores

\begin{tabular}{c|c}
\hline Faixa etária & No de professores \\
\hline 31 a 35 anos & 2 \\
36 a 40 anos & 6 \\
41 a 45 anos & 2 \\
\hline Total & $\mathbf{2 0}$ \\
\hline
\end{tabular}

Fonte: Elaborado pelos autores

As idades distribuídas mostram que os 17 alunos da Escola Pe. Aldo Coppola têm entre 9 e 12 anos, 2 entre 13 e 16 anos e 1 entre 17 e 20 anos. Nessas fases, tanto as crianças quanto aos jovens passam a compreender mais a sociedade, ordens sociais e grupos. Já os professores, 2 tem entre 31 e 35 anos, 6 de 36 e 40 anos, e 2 de 41 e 45, revela que estão num processo de maturidade, adquirindo a estabilidade, ocorre à consolidação profissional no mercado de trabalho, constituição de família, concomitantemente, a mudanças de valores.

Tabela 3 - Raça/cor dos alunos e professores da Escola Pe. Aldo Coppola

\begin{tabular}{c|c|c}
\hline Raça/cor & No de alunos & No de professores \\
\hline Branco & 1 & 1 \\
Pardo & 7 & 5 \\
Preto & 11 & 4 \\
Amarelo & 1 & - \\
\hline Total & 20 & 10 \\
\hline
\end{tabular}

Fonte: Elaborado pelos autores 
O sistema de classificação racial no Brasil não é objetivo, sendo determinado pelas características sociais e pela forma como os entrevistados se autodeclararam. As cinco categorias de pertencimento racial que foram adotadas nos questionários - branco, preto, pardo, amarelo e indígena - seguiram os questionários e formulários que o IBGE utiliza na classificação Brasil. A Escola Pe. Aldo Coppola é formado por maioria de crianças negras e pardas descendente de escravos. E não há como lutar por ideais comuns sem consciência da raça e das tradições.

Assim, de acordo a Tabela 3, sobre raça/cor dos alunos e professores da Escola Pe. Aldo Coppola, sendo os alunos 1 branco, 7 pardo, 11 preto e 1 amarelo. E os professores 1 branco, 5 pardo e 4 preto. Nesse contexto, alunos e professores são em maioria negra e parda, fato que deve servir para ajudar a reforçar os laços que os unem e facilitar a conscientização dos problemas que ser descendente de africanos trouxe para as antigas e novas gerações, como as mazelas da escravidão, o legado de políticas públicas ineficazes, as dificuldades de superação da pobreza.

A qualificação dos professores da Escola Pe. Aldo Coppola, apresenta, 2 com o ensino médio em magistério e os demais no ensino superior, 5 da área de Pedagogia e 1 em cada uma das áreas de História, Biologia e Química. Sendo que 1 professor possui pós-graduação em Psicopedagogia e outro em Educação Especial. Perante esta situação é inegável a necessidade de atualização e qualificação dos professores. Acredita-se que a formação e atualização dos professores, tanto na graduação quanto na pós-graduação, dialoga com o ensino/aprendizagem da realidade escolar da Escola Pe. Aldo Coppola.

Nessa perspectiva, a lógica da política educacional é garantir o direito à educação para todos, investir na escola básica significa investir na educação profissional e na educação superior porque elas estão ligadas direta ou indiretamente. Significa também envolver todos - pais, alunos professores e gestores, em iniciativas que busquem o sucesso e a permanência do aluno na escola proporcionando a reflexão crítica dos indivíduos, a construção da autonomia e a consolidação dos princípios democráticos.

\section{Infraestruturas Comunitárias}

As moradias dos 20 alunos possuem energia elétrica, proporcionada pelo Programa Luz para Todos do Governo Federal. Na comunida- 
de não há água encanada e o abastecimento é realizado de acordo aos respondentes: 1 aluno disse que é de carro pipa, 18 alunos disseram que é através da cisterna, e somente 1 aluno não soube informar como se dá o abastecimento em sua residência (Quadro 1).

Quadro 1- Infraestruturas Comunitárias

\begin{tabular}{|l|l|c|}
\hline Indicadores & Alunos & Frequência \\
\hline Energia elétrica & Energia elétrica & 20 \\
\hline \multirow{2}{*}{ Fornecimento de } & Carro pipa & 1 \\
& Cisternas & 18 \\
& Outro & 1 \\
\hline Esgotamento & Fossa séptica & 20 \\
\hline \multirow{3}{*}{ Resíduos Sólidos } & Coleta diária & 6 \\
& Queimado & 13 \\
& Terreno baldio & 1 \\
\hline \multirow{2}{*}{ Pavimento da rua } & Asfaltada & 2 \\
& Terra & 18 \\
\hline
\end{tabular}

Fonte: Elaborado pelos autores

Na comunidade não há sistema de esgotamento, por isso os 20 alunos utilizam fossa séptica para o uso do esgoto doméstico, que é uma estrutura necessária às moradias, sendo fundamentais no combate a doenças, verminoses e endemias (como a cólera), pois diminuem os lançamentos dos dejetos humanos diretamente no solo. $\mathrm{O}$ seu uso é essencial para a melhoria das condições de higiene da população. $\mathrm{O}$ destino dos resíduos sólidos, 6 tem coleta diária, para 13 alunos o lixo domiciliar é queimado e 1 aluno deposita o lixo em terreno baldio o que afeta o meio ambiente.

A pavimentação asfáltica só existe na avenida principal da comunidade que dá acesso à escola e à unidade básica de saúde. A pavimentação de ruas leva mais qualidade de vida para a população, mas somente 2 alunos moram na rua asfaltada e 18 alunos moram em rua de terra. A prefeitura precisa garantir infraestrutura nas demais vias para além do visual, essas obras trazem mais qualidade de vida aos cidadãos, colocando um fim ao convívio diário com a poeira e a lama na frente de casa. 


\section{Moradias}

O direito à moradia marca a necessidade básica do homem, sendo condição imprescindível para uma vida plena. Ter um lugar para desenvolver-se e permanecer está ligado aos interesses do indivíduo, pois para alcançar as necessidades básicas da vida como relaxar, educar-se, trabalhar, faz-se necessário um lugar firme e amplamente reconhecido por todos (SOUZA, 2004). Partindo desse pressuposto, dos 20 alunos que responderam ao questionário em relação aos aspectos de construção de suas moradias, 18 alunos disseram que moram em casa construida de blocos (tijolos de cimento), enquanto 2 alunos vivem em casa construida de adobe (tijolo de terra crua). Dessa forma, todos os alunos possuem sua casa própria.

Diante disso, o direito à moradia como posse exclusiva de um lugar onde se tenha um amparo, que se resguarde a intimidade e se tenha condições para desenvolver práticas básicas da vida, o mínimo necessário para que o aluno junto a sua família tenha uma vida de dignidade plena, pois, de nada vale o indivíduo ter garantida a vida se não tem um lugar fixo para se proteger, desenvolver-se, descansar, reproduzir, uma moradia que the de possibilidade um desenvolvimento pleno.

Tabela 4 - Quantidade de pessoas que residem no domicílio

\begin{tabular}{l|c}
\hline Pessoas por domicílio & No de alunos \\
\hline Entre 3 e 4 pessoas & 2 \\
Entre 5 e 6 pessoas & 12 \\
Entre 7 e + & 6 \\
\hline Total & 20 \\
\hline
\end{tabular}

Fonte: Elaborado pelos autores

Sobre o número de pessoas que habitam a mesma habitação, 2 alunos responderam que tem entre 3 e 4 pessoas no domicílio, 12 alunos afirmaram ter entre 5 e 6 pessoas e 6 alunos responderam que tem 7 e + membros no mesmo agregado familiar, a condição no domicílio é caracterizado por meio da relação existente entre a pessoa responsável pelo domicílio e cada um dos demais moradores. Dito isso, moradia, onde acontece o relacionamento entre seus ocupantes é ditado por laços de parentesco, de dependência doméstica ou por normas de convivência. 
Para Mira, "[...] o tipo de organização familiar não só reflete as crenças e os valores tradicionais existentes no espaço geográfico residencial, como influência a organização das próprias atividades econômicas" (MIRA, 2014, p. 4). Na família os filhos e demais membros encontram o espaço que lhes garantem a sobrevivência, desenvolvimento, bem-estar e proteção integral através de aportes afetivos e, sobretudo, materiais. A família é o eixo de referência pelo qual os seus participantes elaboram e determinam suas relações sociais, além de ser o apoio para que homens, mulheres e crianças se organizem em torno da realização de projetos comuns (MIRA, 2013).

\section{Renda Mensal}

Tabela 5 - Renda mensal

\begin{tabular}{l|c}
\hline Renda familiar & No de alunos \\
\hline - 1 salário mínimo & 8 \\
1 salário mínimo & 7 \\
+1 salário mínimo & 5 \\
\hline Total & 20 \\
\hline
\end{tabular}

Fonte: Elaborado pelos autores

O salário mínimo é essencialmente um salário político, isto é, um piso de remuneração abaixo do qual a sociedade considera a remuneração do trabalho insuficiente/injusta para uma vida digna. Capaz de atender as necessidades básicas e às de sua família com moradia, alimentação, educação, saúde, lazer, vestuário, higiene, transporte e previdência social, com reajustes periódicos que lhe preservem o poder aquisitivo, sendo vedada sua vinculação para qualquer fim. Nesse sentido, a maioria dos alunos pertence a famílias de baixa renda, visto que 8 famílias vivem com menos de 1 salário mínimo, 7 vivem com 1 salário mínimo, e 5 vivem com mais de 1salário mínimo. É necessário que se restabeleça uma trajetória de crescimento sustentado que crie uma capacidade recorrente e respeitável de criação de novos postos de trabalho, isto é, que se facilite a entrada no mercado de trabalho dos membros das famílias de baixa renda, inclusive com níveis de remuneração mais favoráveis. 
Em 2017 o valor correspondente do salário mínimo é de R\$ 937,00 . E a renda é gerada por meio da agricultura e da pecuária. Em maioria, o padrão de vida dessas famílias é simples e desprovido de tecnologias e materiais didáticos no cotidiano, chegando muitas vezes à carência extrema. São, portanto, famílias que dependem do Programa Bolsa Família.

\section{Identidade Comunitária}

Há 11 alunos que conhecem a origem da Comunidade de Castanhão, 9 alunos desconhecem. Não conhecer de onde vieram, as lutas que as gerações anteriores travaram para estabelecer-se, erguer moradia, criar família, é uma grande perda para a autoestima e reconhecimento da importância dos antepassados. Conhecendo a própria cultura, o indivíduo compreenderá a importância de mantê-la viva na memória, protegê-la e valorizar a cultura como forma de preservar o que somos nossas características, nossa identidade. Como lidar com crianças que desconhecem o lugar onde vivem? Como fazê-las valorizar as tradições do povo a que pertencem? Estas são questões pedagógicas em embate constante com o mundo globalizado, que traz desafios à sala de aula.

A escola em Castanhão tem alunos cujos pais Ihes contam a história local, mas metade, 10 alunos não conhecem a história local, e poucos se consideram brancos ou professam outros credos. As crenças não os distinguem, e convivem em harmonia em uma comunidade quilombola. Entre os 10 professores, 9 conhecem a origem da Comunidade de Castanhão, enquanto 1 professor não conhece como foi fundada a comunidade. Isso demonstra a necessidade de conhecer e discutir a atuação de cada professor na escola para melhor contribuir para a realidade cultural dos alunos.

Também 12 alunos se reconhecem como quilombolas, enquanto 8 alunos não se reconhecem como remanescente quilombola. Portanto, a discussão é particularmente importante para introduzir os elementos da luta pelo reconhecimento centrado na afirmação da diferença com aquelas lutas pela igualdade de condições. 10 alunos disseram que a família repassa ensinamentos e experiências vivenciadas como comunidade negra, 10 alunos disseram que não repassa os ensinamentos. $E$ 10 alunos disseram saber o que é quilombo, 10 alunos disseram que não sabem. Quanto ao fato de o reconhecimento como remanescente de 
quilombo poder influenciar-lhes a vida, 17 alunos acreditam que sim, 3 alunos acreditam que não. $\mathrm{O}$ fato de ser remanescente quilombola lhes conferir posição de inferioridade diante das pessoas da cidade para 4 alunos disseram sim, enquanto 16 alunos disseram que não.

Não se ver como quilombola, nem conhecer o que significa isso - e pior, quando se nega a origem - é a realidade concreta de muitos alunos da Comunidade de Castanhão, como se pode ver nas questões respondidas. Rezende da Silva $(2008$, p. 86) afirma que "[...] reconhecer-se 'remanescente de quilombos' é assumir uma identidade político-cultural com a qual se mostra externamente nos embates públicos em defesa de seus direitos, principalmente os relativos à terra".

\section{0 que é um quilombo?}

Numa comunidade quilombola a percepção de identidade étnica é importante para definir as fronteiras do que é inerente à comunidade e o que é influência externa e pode ser ou não relevante.

Ser quilombola é re-elaborado no processo político, no qual, direitos são construídos e ampliados. O crescente número de comunidades que autoidentificam como quilombolas e a diversidade destas apontam a inexistência de uma identidade moldurada (SANTANA, 2008, p. 8).

Para a pergunta "Você sabe o que é quilombo?", houve unanimidade, todos os professores disseram que sim. Acredita-se que o reconhecimento da comunidade como remanescente de quilombo poderia influenciar na própria vida e na dos alunos, assim 9 professores disseram que sim, enquanto 1 professor disse que não. Ao serem perguntados se, para o aluno, o fato de ser remanescente quilombola confere posição inferior diante das pessoas da cidade, todos acreditam que não. Se o conhecimento recebido por meio da educação influencia a identidade dos alunos se e quando a comunidade for reconhecida como remanescente quilombola, 9 professores disseram que sim e 1 professor disse que não. Diante da indagação se o acesso à educação modifica ou fortalece a identidade dos alunos, 9 professores acham que sim e 1 professor disse que não.

$\mathrm{Na}$ Comunidade de Castanhão, a expressão remanescente de quilombo e o ser quilombola ainda são um fato novo a ser apreendido 
pelas famílias, o que vai sendo construído a partir da vivência. E não só isso, mas a luta por direitos iguais. Uma comunidade sem unidade é uma versão distorcida da realidade, algo controverso, ou pelo menos superficial. Uma comunidade deve partilhar ideias e ideais comuns. A escola Padre Coppola é formada por maioria de crianças negras e pardas, reflexo de uma comunidade igualmente de maioria negra e parda, descendente de escravos. E não há como lutar por ideais comuns sem consciência da raça e das tradições.

As entrevistas: a comunidade “já passou da hora de ser reconhecida"

Os remanescentes de quilombo são definidos como grupos étnico-raciais que têm uma trajetória histórica própria, dotados de relações territoriais específicas, com presunção de ancestralidade negra relacionada à resistência e opressão histórica sofrida, devendo sua caracterização ser dada segundo critérios de autoatribuição atestada pelas próprias comunidades, como adotado pela Convenção da OIT sobre Povos Indígenas e Tribais, que constam na legislação brasileira (BRASIL, 2004).

As entrevistas semiestruturadas tratam dos aspectos da comunidade, origem, história de fundação e certificação, crenças, tradições, atividades cotidianas, trabalho, entendimento sobre o que é ser quilombola a Comunidade Remanescente e foram aplicada a 3 homens e 1 muIher ditos guardiães da comunidade.

As experiências vividas e percebidas nas diversas narrativas dos entrevistados, refletem a sua condição de resgatar a importância de ser quilombola. Diz José Rufino da Silva ("Seu Ziquinha", com 79 anos em 03/11/2016), que: "eu posso falar porque aqui já passou de ter uma comunidade quilombola, se aqui fosse uma comunidade bem desenvolvida - aqui é um lugar que podia ter uma comunidade quilombola". Cada percurso individual por essas experiências confunde-se com a história de vida, modificando-a e dando-lhe novos sentidos. Assim, Sebastiana Rosa da Conceição ("Tiana" com 73 anos em 03/11/2016), diz: "o meu pai era, mas minha mãe não, mas o meu pai sim. Quilombola são pessoas negras, são pessoas que foram excluído naquela época da escravidão". Para José Pereira da Silva ("Seu Dé" com 75 anos em 03/11/2016), relata ser de "origem negra". E por fim, Brasiliano Francisco da Silva, (89 anos em 03/11/2016), diz: "não sei se meu avô veio do cativeiro. Era tudo moreno". Sobretudo, as narrativas de 
vida que trazem mais fortemente essa dimensão de revelação da pessoa, dando um sentido a sua experiência.

Diante das afirmativas dos entrevistados, deve-se primeiro conhecer a história da própria cultura, saber como se deu essa construção e como foi o processo de evolução e desenvolvimento da mesma. Conhecendo a própria cultura, os idosos compreendem a importância de mantê-la viva na memória, protegê-la e valorizar a cultura como forma de preservar as suas características, sua identidade. Pode-se dizer que uma comunidade é um grupo de seres humanos que partilham elementos em comum, os costumes, a localização geográfica, a visão do mundo ou os valores.

\section{O Papel da Escola na Formação Identitária}

No contexto educacional brasileiro, de acordo com diversos critérios, procuram-se sistematizar as teorias educacionais a fim de se tornarem instrumentos de análise da prática educativa. Implica necessariamente na análise do processo educativo e sua dimensão. Visto que, a ação educativa é um processo de relações humanas, uma atividade de interação entre quem ensina e quem aprende, ou seja, ensinar e aprender acontece no desenrolar da interação entre o professor e o aluno, cujo vínculo é intencional, isto é, existe uma intenção de transformação de ideias e atitudes daqueles que compreendem pelos que ensinam.

Todavia, para os alunos, o conhecimento recebido por meio da educação pode influenciar a identidade quando a comunidade for reconhecida como remanescente quilombola, 15 alunos acreditam que sim, 5 alunos não acreditam. E 9 alunos respondentes disseram que gostariam que a terra onde vivem fosse reconhecida como propriedade da comunidade quilombola, 11 alunos disseram não. Para a pergunta se trabalha a história da comunidade com os alunos, 7 professores responderam que sim, 3 professores responderam que não. Este resultado reflete no Projeto Político Pedagógico, pois todos os professores deveriam trabalhar a história da comunidade, e envolver-se nas atividades do Projeto Cultura Afro-Brasileira, proposto em 2015 e que continuou a valer em 2016. E também da Lei no 10.639/03 (BRASIL, 2003), que versa sobre o ensino da história e cultura afro-brasileira e africana, ressalta a importância da cultura negra na formação da sociedade brasileira. 
Sobre tempo de magistério e tempo de trabalho na Escola Pe. Aldo Coppola (Tabela 6).

Tabela 6 - Tempo de Formação no Magistério e de trabalho na Escola Pe. Aldo Coppola

\begin{tabular}{c|c|c}
\hline Tempo & $\begin{array}{c}\text { Tempo de Formação } \\
\text { no magistério }\end{array}$ & $\begin{array}{c}\text { Tempo de trabalho na } \\
\text { Escola Pe. Aldo Coppola }\end{array}$ \\
\hline 1 a 5 anos & 3 & 6 \\
6 a 10 anos & 2 & 1 \\
11 a 15 anos & 3 & 2 \\
16 a 20 anos & 2 & 1 \\
\hline Total & 10 & 10 \\
\hline
\end{tabular}

Fonte: Elaborado pelos autores

Dos 10 professores que responderam ao questionário, quanto à formação do magistério, o tempo laboral corresponde: 3 tem 1 a 5 anos, 2 tem 6 a 10 anos, 3 tem 11 a 15 anos e 2 tem 16 a 20 anos. E quanto ao tempo de efetivo serviço na Escola Pe. Aldo Coppola corresponde: 6 de 1 a 5 anos, 1 de 6 a 10 anos, 2 de 11 a 15 anos e 1 de 16 a 20 anos. Os dados demonstram tempo de formação a que cursou o magistério e o tempo que lecionam na comunidade.

Sobremodo, quando questionados aos professores quais os materiais didáticos mais utilizados em suas aulas, 6 disseram que o material mais utilizado em sala de aula é o livro didático, enquanto 4 disseram que o material didático mais utilizado é a apostila elaborada pelo professor. Esses 6 professores informaram que trabalham a história dos quilombos com os alunos, enquanto os 4 professores disseram que não. Os que trabalham a história dos quilombos em sala aplicam o Projeto Cultura Alfa, projetos de cultura afro-brasileira e sequência didática, feira cultural e vídeos documentários. Todos os professores conhecem a Lei no 10.639/03 e aplicam-na tanto a matriz curricular quanto o projeto político pedagógico da escola. Também disseram conhecer as Diretrizes Curriculares Nacionais e o Ensino da História e Cultura Afro-Brasileira e Africana (2004).

Quanto à participação da família na escola, 19 alunos disseram que os pais a visitam apenas quando a presença dos pais é solicitada pela instituição; 1 aluno disse que a família visita a instituição de ensino pelo menos duas vezes durante o ano letivo. 
Para a questão sobre relação entre escola, comunidade e família (Tabela 7).

Tabela 7 - Relação entre escola, comunidade e família

\begin{tabular}{l|c}
\hline Relação & No de professores \\
\hline Espaço & 1 \\
\hline Parceria & 1 \\
\hline Participação & 2 \\
\hline Educação de qualidade & 1 \\
\hline Democratização do Ensino & 1 \\
\hline Troca de saberes & 1 \\
\hline Total & 7 \\
\hline
\end{tabular}

Fonte: Elaborado pelos autores

A escola precisa da participação dos familiares, o trabalho em conjunto da família com a escola demonstra ser uma das estratégias mais eficazes para o sucesso do ensino, sem falar que, a partir do momento em que os familiares participam de forma ativa na escola, fica mais fácil envolver toda a comunidade, afinal a família é a célula vital de uma sociedade. A família pode ser concebida, ainda, como uma ponte que liga escola e comunidade. Sobre a relação entre escola, comunidade e família: 1 Espaço, 1 Parceria, 2 Participação, 1 Educação de qualidade, 1 Democratização do ensino e 1 Troca de saberes. Estes resultados mostram que em todo processo de aprendizagem humana, a interação social e a mediação do outro têm fundamental importância.

Quando perguntados se os pais procuram a escola, todos os professores afirmaram que sim. E se os pais reclamam de alguma coisa, a opinião ficou dividida: 5 professores disseram que sim e 5 professores disseram não, sendo as reclamações relacionadas ao espaço físico da escola. Apenas 1 professor disse que os pais costumam sugerir algum conteúdo ou atividades escolares, os outros 9 professores responderam que não. Segundo Mira (2013), a família assegura o conhecimento e acatamento das normas do grupo social e ideologias dos grupos identitários. Em casa, inicia-se a educação que o aluno já levará ao ambiente, conteúdos que traz da convivência familiar. $O$ trabalho familiar em conjunto é 
uma das estratégias eficazes para o sucesso da atividade escolar. Como célula, a família que participa da escola ajuda a envolver a comunidade.

Desde que a identidade dos sujeitos é elaborada no inter-relacionamento de processos educativos que acontecem em várias instâncias espaçotemporais, durante a investigação histórica do quilombo e das bases formativas da identificação dos sujeitos, buscou-se compreender como funciona o estabelecimento dessa identidade e como os mais velhos transmitem os valores da comunidade e como os professores e a família dos alunos trabalham essas questões, quais métodos foram acoIhidos e professados na educação e formação do indivíduo quilombola.

Acreditando na relevância dessa discussão, numa nova postura de formação dos indivíduos primando pelo desenvolvimento humano, a educação emerge como processo da sociedade em cada espaço/tempo histórico, sendo a escola um lócus privilegiado de criação/(re) construção/ reprodução de conhecimentos. O que possibilita a compreensão das práticas pedagógicas escolares enquanto práticas sociais específicas dos processos de ensinar e aprender e suas relações com as outras práticas sociais.

\section{Conclusões}

1. A construção histórica da identidade remanescente quilombola de crianças negras no espaço escolar da Comunidade de Castanhão, efectua-se por meio da transmissão da cultura e valores, desde a fundação do povoado em colaboração com a escola, porque a identidade étnica é importante para definir as fronteiras. $\mathrm{Na}$ Comunidade de Castanhão, a expressão remanescente de quilombo e o ser quilombola são um fato novo a ser apreendido pelas famílias.

2. Um mergulho na Comunidade de Castanhão, numa convivência presente no dia a dia, dividindo valores e expectativas desse povo por muito tempo marginalizado, a fim de ajudar a ampliar o conhecimento sobre os processos de formação, de educação formal e escolar, de construção da identidade, de transmissão de valores éticos, morais e culturais da antiga para a nova geração.

3. A qualificação profissional está cada vez mais presente na vida dos professores da Escola Pe. Aldo Coppola que obtiveram graduações e também na pós-graduação. Acredita-se que a formação leva os professores a uma reflexão sobre a sua prática. 
4. O direito à moradia marca a necessidade básica do indivíduo, sendo imprescindível para uma vida plena. Ter um lugar para desenvolverse e permanecer faz-se necessário um lugar firme e amplamente reconhecido por todos. A política de reconhecimento da diferença conduz a discussão sobre qual o papel a ser desempenhado pelo conhecimento antropológico na defesa da diversidade cultural e do potencial crítico desses outros modos de ser e viver.

5. A infraestrutura da comunidade é precária o que afeta o Ensino/ Aprendizagem dos alunos da Escola Pe. Aldo Coppola. Visto que, poucas ruas são asfaltadas, não há água encanada, o lixo é na maioria dos domicílios queimado e não há sistema de esgotamento, sendo utilizada ainda, a antiga fossa séptica.

6. A Escola Padre Aldo Coppola é formada por maioria de crianças negras e pardas, reflexo da tipologia da comunidade.

7. A temática identidade e educação é marcada pela diversidade, que envolve uma série de padrões culturais que guiam as definições, as políticas públicas e a visão de mundo da comunidade. Nesse debate, na Comunidade de Castanhão, a expressão remanescente de quilombo e o ser quilombola são um fato novo a ser apreendido pelas famílias, o que vai sendo construído a partir da vivência.

8. Os professores de crianças quilombolas necessitam entender e refletir sobre as diferenças étnico-raciais e culturais; não discriminar, entender as diferenças e aprender a respeitá-las; valorizar a história e o orgulho da raça, mobilizar famílias e comunidade em ações conjuntas de socialização e harmonização de objetivos comuns num compromisso com o Projeto Cultura Afro-Brasileira, carro-chefe do Projeto Político Pedagógico da escola.

9. A identificação de remanescente de quilombo foi sendo elaborado pelo reconhecimento de um passado comum e construído em situação de conflito e de sobrevivência. $O$ critério de autoatribuição constitui um recurso para tornar possível a efetivação de um direito fundamental à memória dos descendentes de quilombo - de terem a terra preservada para preservar a própria cultura.

10. A partir das Diretrizes Curricular Quilombola, faz-se necessário um diálogo pedagógico sobre a identidade e a cultura quilombola, e perceber que elementos do currículo escolar podem e devem ser transformados em conteúdos escolares de valores histórico e simbólico. 


\section{Referências}

BOYD, R.; RICHERSON, P. J. The origin and evolution of cultures. Oxford/ USA: Oxford University Press, 1985.

BAUMAN, Z. Comunidade: a busca por segurança no mundo atual. Rio de Janeiro: Jorge Zahar Ed. , 2003.

BRASIL. Diretrizes Curriculares Nacionais para a Educação das Relações Étnico-Raciais e para o Ensino de História e Cultura AfroBrasileira e Africana. Brasília: (s/n), 2004.

BRASIL. Lei n. 10.639, de 9 de janeiro de 2003. Altera a Lei no 9. 394, de 20 de dezembro de 196, que estabelece as diretrizes e bases da educação nacional, para incluir no currículo oficial da Rede de Ensino a obrigatoriedade da temática "História e Cultura Afro-Brasileira", e dá outras providências. Presidência da República. Brasília, 2003.

CABANAS, J. M. Q. Teoria da Educação: Concepção antinômica da educação. Edicções ASA, Portugal, 2002.

FREIRE, P. À sombra desta mangueira. 2 ed. São Paulo: Olho d'Água, 1996.

HALL, S. A Identidade cultural na pós-modernidade. 11. ed. Rio de Janeiro: DP\&A, 2006.

. Identidade e diferença: uma introdução teórica e conceitual. In: SILVA, Tomaz T. (org.), HALL, Stuart; WOODWARD, Kathryn. Identidade e diferença: a perspectiva dos estudos culturais. Petrópolis, RJ: Vozes, 2000.

HARNIK, S. Brasil: 8 em 10 professores da educação básica são mulheres. UOL, Educação. Todos Pela Educação, 03/03/2011. Disponível em <https://educacao.uol.com.br/noticias/2011/03/03/brasil-8-em-10 -professores-da-educacaobasica-sao-mulheres.htm?cmpid=copiae cola>. Acesso em 15 mai. 2016.

MEC. Educação quilombola - apresentação. Disponível em <http:// portal.mec.gov.br/educacao-quilombola->. Acesso em 28 fev. 2016.

. Todos pela Educação. Disponível em <http://todospela educacao.org.br/educacao-na-midia/indice/26965/educacao-paracomunidades-quilombolas-e-um-desafio/>. Acesso em 28 fev. 2016. 
MIRA, F. Ao correr do olhar - desafios para uma epistemologia metafórica. Edição experimental. Oficina do Espírito. Arraiolos/PT: Edições Subjectivas, 2013.

As cores da economia e o desenvolvimento sustentável in MARQUES, Juracy (org. ). Ecologias humanas. Feira de Santana-BA: UEFS, 2014. 462 p. Disponível em <http://www. sabeh. com. br/arquivos/ EcologiasHumanas. pdf >. Acesso em 02 set. 2015.

Portugal Engalanado por Mares Tecidos a Ponto Cruz. In: Nuno Miguel Augsto. (Org.). Sociedade em Debate. 1 ed.Vila Nova de Famalicão: Humus, 2016.

Dimensões Económicas da Crioulidade in ANAIS DA UNIVERSIDADE DE ÉVORA, 1997

MORENO, A. C. Brasil cai em ranking mundial de educação em ciências, leitura e matemática. G1, 6 dez. 2016. Disponível em: <https:// g1.globo.com/educacao/noticia/brasil-cai-em-ranking-mundial-deeducacao-em-ciencias-leitura-e-matematica.ghtml>. Acesso em: Acesso em 21 jan. 2017.

REZENDE DA SILVA, S. Negros na Mata Atlântica, territórios quilombolas e a conservação da natureza. 2008. 360f. Tese (Doutorado em Geografia Física) - Faculdade de Filosofia, Letras e Ciências Humanas, Universidade de São Paulo. São Paulo, 2008.

SANTANA, G. B. B.. Terras de uso comum e identidades coletivas: ressignificando o conceito e a função da propriedade. 2008. Disponível em <http://www.ibdu.org.br/imagens/ TERRASDEUSOCOMUMEIDENTIDADESCOLETIVAS.pdf>. Acesso em 13 set. 2016.

SOUZA, M. L. A.. Ser quilombola: identidade, território e educação na cultura infantil. 265f. Tese (Doutorado em Educação) - Faculdade de Educação, Universidade Estadual de Campinas, Campinas, SP. 2015. Disponível em <http://www.bibliotecadigital.unicamp.br/ document/?down=000963444 > . Acesso em 03 out. 2016.

SOUZA, S. I. N. Direito à Moradia e de Habitação: Análise Comparativa e suas Implicações Teóricas e Práticas com os Direitos da Personalidade. São Paulo: Editora Revista dos Tribunais, 2004. Disponível em <http://www. 
ambito-juridico.com.br/site/?n_link=revista_artigos_leitura\&artigo_ $\mathrm{id}=13677>$. Acesso em 13 de jul. 2017.

WOODWARD, K. Identidade e diferença: uma introdução teórico e conceitual. In SILVA, Tomaz Tadeu da. Identidade e diferença. A perspectiva dos Estudos Culturais. Petrópolis: Vozes, 2000.

Recebido em julho/ 2017

Aceito em abril/2018 